\title{
Apoptosis Involved in Density-dependent Regulation of Rat Fibroblastic 3Y1 Cell Culture
}

\author{
Toshiharu Yasaka ${ }^{1}$, Satoshi Ichisaka ${ }^{1}$, Tetsuo Katsumoto ${ }^{1}$, Hirotoshi Maki ${ }^{1}$, Makoto Saji ${ }^{1}$, Genki \\ Kimura $^{2}$, and Kousaku Ohno ${ }^{1 *}$ \\ ${ }^{1}$ Department of Neurobiology, School of Life Science, Tottori University Faculty of Medicine, 86 Nishimachi, \\ Yonago 683, Japan and ${ }^{2}$ Department of Virology, Medical Institute of Bioregulation, Kyushu University \\ Maidashi 3-1-1, Fukuoka 812, Japan
}

Key words: apoptosis/density-dependent regulation/contact inhibition/cell culture/3Y1 cell

\begin{abstract}
$A B S T R A C T$. When rat $3 Y 1$ fibroblastic cells are cultured toward confluency, the cells go through maximum cell density (overshoot) before reaching post-confluence stationary cell density. After overshooting, a number of floating cells are found in the medium. In a long-term culture, a cyclic change in cell number, an increase after each medium refreshment and subsequent cell loss within a few days has been observed so that the cell populations in the monolayer maintain post-confluence stationary cell density at a constant level. The floating cells excluded trypan blue, but they had no ability to attach to the substrate and to form colonies after being reseeded in fresh medium. They had condensed and uniformly electron-dense chromatin with sharply circumscribed edges. Their DNA contained a laddering pattern in harmony with internucleosomal cleavage. The features were those of apoptosis. When floating cells appeared, apoptotic bodies were also observed in the monolayer. Most of them were found within the cytoplasm of intact cells, suggesting that apoptotic bodies were also faded away from the culture by being rapidly engulfed by neighboring intact cells. These suggest that apoptosis and subsequent detachment from the monolayer or engulfment by neighboring intact cells, in addition to inhibition of cell division, are basic mechanisms on the process of density-dependent regulation in monolayer culture of rat $3 Y 1$ cells.
\end{abstract}

It has long been assumed that cells must be lost continuously from many normal tissues to retain balance in the process of cell division. A number of apoptotic bodies have been found in histological sections of many healthy animal tissues and many believe that apoptosis plays an important role in the regulation of normal cell populations (1; for review see ref. 2). In tissue cultures, "normal" cell lines stop dividing at stationary cell densities proportional to the serum concentration in the culture medium, which is known as "contact inhibition" or "density-dependent inhibition" of cell division (3). There has been considerable discussion in the literature about mechanisms which lead to density-dependent inhibition of cell division in cultures of normal animal cells (3-6); by contrast little attention has been paid to controlled cell deletion. The adjustment of stationary cell densities in normal cell cultures may be determined not only by inhibition of cell division but also cell loss from the monolayer. Primary cultures of rabbit uterine

\footnotetext{
* Corresponding Author Kousaku OHNO, M.D. Department of Neurobiology, School of Life Sciences, Tottori University Faculty of Medicine, 86 Nishimachi, Yonago 683, Japan.

Tel: 0859-34-8275, Fax: 0859-34-9209
}

epithelial cells exhibit cyclic changes in DNA content and cell number throughout extended periods of culturing (7). Cell death in primary uterine epithelial cell cultures has features of apoptosis both morphologically and biochemically (8) and coordinated regulation of cell proliferation and apoptosis has been proposed in order to maintain homeostasis in the total culture mass of normal primary or early passage cell cultures $(7,8,9)$. However, it has been questioned whether some established cell lines may also exhibit coordinated regulation of apoptosis and cell proliferation under standardized culture conditions because they were selected on the basis of continuous proliferation (9). The mouse immortalized 3T3 cell line has been known to go through maximum cell density before reaching stationary cell density by net cell loss and that, during cell loss, it has been observed that some cells become pyknotic, detached from the substratum and disintegrate, suggesting that a density-dependent cell death is an important process during adjustment of stationary cell density (10). Several reports describe apoptosis as occurring in a variety of established cell lines other than thymocytes or lymphocytes under specific nutritional conditions such as the deprivation of serum or growth factors $(11,12)$ or in the 
presence of inhibitors of cell cycle progression (13).

The rat 3Y1 cell line (14) is diploid fibroblastic cell line with high serum requirements. The cells stop synthesizing DNA and are arrested in a G1/G0 state displaying a typical "cobblestone" appearance at saturation densities which are dependent on serum concentrations. This cell line has been used as a model system for studying the regulation of "normal" cell proliferation $(15,16,17,18,19)$. When $3 Y 1$ cells are cultured toward confluency, cell numbers go through maximum cell density (overshoot) before reaching postconfluence stationary cell density. In a long term culture with renewals of medium of $10 \%$ serum once a week, the $3 \mathrm{Y} 1$ cells showed a cyclic change in cell number, an increase after each medium refreshment and a decrease equivalent to the increase within a few days (20). However, their chemically transformed sublines showed a stepwise increase in cell number resulting from a reduction or a diminution of cell loss rather than enhanced cell division after medium renewals (20). This phenomenon suggested to us that coordinated regulation of cell division, density-dependent inhibition of cell division and density-dependent cell death are part of a basic process in maintaining post-confluence stationary cell density at a constant level in "normal" cell culture. Basically, in this paper, we want to discuss our findings on whether or not apoptosis is involved in the maintenance of postconfluence stationary cell density.

\section{MATERIALS AND METHODS}

Cell Culture. A clonal diploid fibroblastic cell line established from a Fischer rat embryo, 3Y1-B clone 1-6 (referred to as 3Y1) (14) was cultivated in a 35, 60 and $90 \mathrm{~mm}$ plastic dish (Sumitomo Bakelite, Tokyo) in 2, 5 or $13.5 \mathrm{ml}$ of Dulbecco's modified Eagle's medium (GIBCO, Berkeley, Calif.), respectively, with $500 \mathrm{IU} / \mathrm{ml}$ penicillin $\mathrm{G}, 100 \mathrm{mg} / \mathrm{ml}$ streptomycin sulfate and $10 \%$ fetal bovine serum in humidified air containing $10 \% \mathrm{CO}_{2}$ at $37^{\circ} \mathrm{C}$. Dispersion of cells for cell transfer and cell number determination was done using $0.05 \%$ trypsin and $0.54 \mathrm{mM}$ EDTA in $\mathrm{Ca}^{2+}$ and $\mathrm{Mg}^{2+}$ free phosphate-buffered saline (PBS). Cell number was determined with a hemocytometer. To examine cell viability, a dye exclusion test was done using trypan blue.

Nuclear staining by 33258 Hoechst and acridine orange. To stain the nucleus of cells in the monolayer, cells were washed with PBS twice, fixed in 3.7\% formaldehyde for 10 min, and stained with Hoechst 33258 (500 $\mathrm{ng} / \mathrm{ml}$ in PBS) at room temperature for $30 \mathrm{~min}$. To stain floating cells in the medium, the medium was transferred into a conical plastic tube and cells were fixed by the addition of $1 / 10 \mathrm{vol}$ of $37 \%$ formaldehyde solution for $10 \mathrm{~min}$ and then contrifuged at $1,000 \mathrm{rpm}$ for $10 \mathrm{~min}$. Cells were resuspended in PBS, stained with 500 $\mathrm{ng} / \mathrm{ml}$ Hoechst 33258. Acridine orange has been reported to selectively stain apoptotic forms of cell death in Drosophila embryos (20). Cells on monolayer were fixed and were stained with acridine orange at a final concentration of $5 \mu \mathrm{g} / \mathrm{ml}$ in $\mathrm{PBS}$ at room temperature. Stained cells were observed under a fluorescence microscope (Olympus BH-2) at an excitation wavelength of UV (33258 Hoechst) or at an excitation wavelength of B (acridine orange).

Electron microscopy. For observation of cells in the monolayer, cells were cultured on a plastic-sheet (Wako Pure Chemical Industries, Ltd) and were fixed in $2.5 \%$ glutaraldehyde in PBS for $30 \mathrm{~min}$ after gently rinsing the monolayer twice with PBS. Floating cells were collected from the medium by centrifuging at $1,500 \mathrm{rpm}$ for $5 \mathrm{~min}$. After washing in PBS, cells were fixed in $2.5 \%$ glutaraldehyde in PBS for 30 min at room temperature and washed twice with PBS. The cell suspension was dropped on a plastic-sheet coated with $0.1 \%$ poly-L-lysine, and cells were allowed to attach to the substrate for $5 \mathrm{~min}$. Cells cultured on the plastic-sheet and floating cells attached on the plastic-sheet were post-fixed with $1 \% \mathrm{OsO}_{4}$ in PBS for $30 \mathrm{~min}$, washed in PBS for $5 \mathrm{~min}$ three times, treated with $0.2 \%$ tannic acid for $30 \mathrm{~min}$, and then washed in distilled water three times. The plastic-sheet was cut into small pieces of $5 \times 10 \mathrm{~mm}$. Cells on the plastic-sheet were dehydrated in 50,70 and $90 \%$ ethanol for 10 min each and absolute ethanol for $5 \mathrm{~min}$ three times. These plastic-sheets with cells were embedded in epoxy resin, and thin $(90 \mathrm{~nm})$ sections were prepared in parallel or perpendicular to the surface of the substratum. The sections were stained with uranyl acetate and lead citrate and then observed under a Hitachi HU-12 electron microscope at $100 \mathrm{kv}$.

DNA extraction and agarose gel electrophoresis. Cells cultured in a $90 \mathrm{~mm}$ dish were washed with PBS, harvested with a cell scraper and pelleted. Cells floating in the medium were collected from about twenty $90 \mathrm{~mm}$ dishes, centrifuged at $2500 \mathrm{rpm}$ for $10 \mathrm{~min}$ and, after washing with PBS, were pelleted. The pellets were lysed with $1 \mathrm{ml}$ of $1 \mathrm{mM}$ EDTA, 10 $\mathrm{mM}$ Tris- $\mathrm{HCl}(\mathrm{pH} 7.5)$ containing $0.5 \%$ SDS and $0.1 \mathrm{mg} / \mathrm{ml}$ proteinase $\mathrm{K}$. After incubation for $4 \mathrm{~h}$ at $50^{\circ} \mathrm{C}$, the lysate was washed with phenol-chloroform. The DNA solution was then incubated with $0.02 \mathrm{mg} / \mathrm{ml}$ RNase A for $1 \mathrm{~h}$ at $37^{\circ} \mathrm{C}$. Samples were electrophoresed on a $1.5 \%$ agarose gel. The DNA was stained with ethidium bromide.

\section{RESULTS}

Proliferation of $3 Y 1$ cells in a long term culture and the morphological appearance of floating cells in the medium. When the $3 \mathrm{Y} 1$ cells were inoculated at a low cell density in medium with $10 \%$ FBS, the cells proliferated exponentially and then reached an initial saturation density of around $1 \times 10^{6}$ cells $/ 60 \mathrm{~mm}$ dish. Before reaching saturation density, the cell population passed through a maximum cell density of around $1.3 \times 10^{6} /$ dish. When the medium was renewed after the attainment of the initial saturation density, the cells doubled and passed through a second maximum cell density of about $2 \times 10^{6}$ 


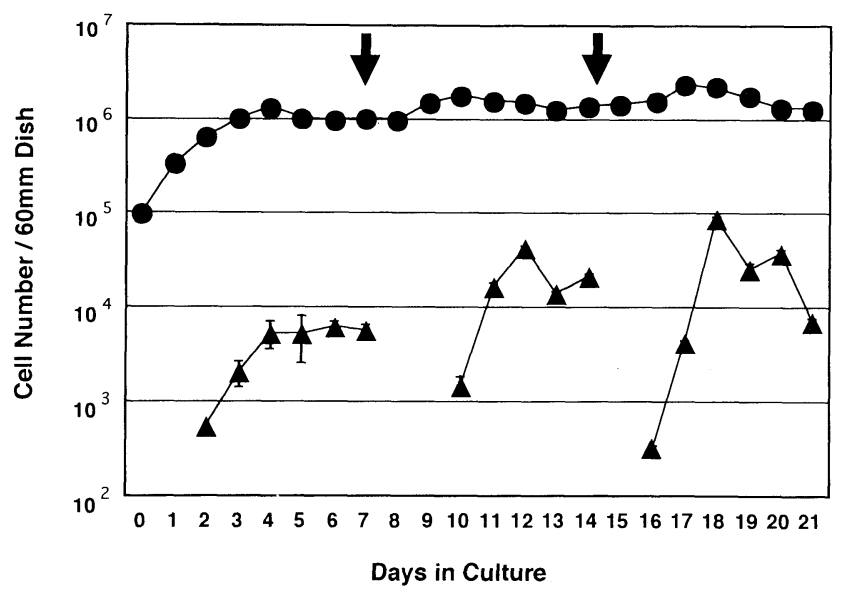

Fig. 1. Change in cell number of rat $3 Y 1$ cells cultured (O) throughout an extended period in DMEM with 10\% FBS with medium renewals $(\downarrow)$ once a week, and cells floating in medium $(\boldsymbol{\Delta})$. All points are mean \pm SD of triplicated dishes.

/dish. The cultures then reached the second saturation density of about $1.5 \times 10^{6} /$ dish by decreasing a cell number. Afterward, the $3 Y 1$ cultures maintained the second saturation density at a constant level with a cyclic change in cell number, increasing upon medium renewals and decreasing equivalent to the increase within a few days (Fig. 1), confirming our previous observation (20). When the cultures went from the maximum cell density to the saturation cell density, a number of floating cells in the medium were observed (Fig. 2). The floating cells were round but the sizes were variable and smaller than the mitotic cells. They were viable in terms of the trypan blue dye exclusion but the cells reseeded in fresh medium were unable to attach and to proliferate.
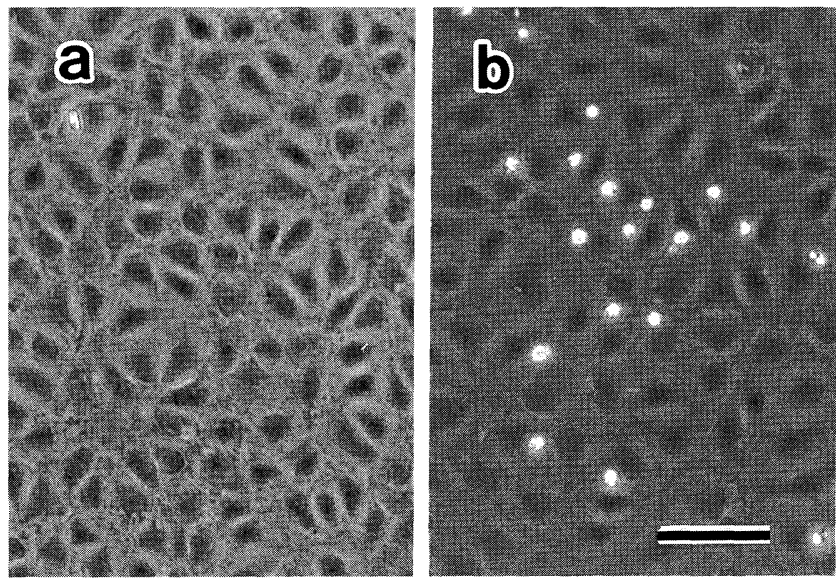

Fig. 2. The monolayer cell just reaching the maximum density (a) and reaching the stationary cell density at 5 days after a medium renewal of confluent culture (b). Note floating cells in medium and decreased cell density in the monolayer of the stationary phase (b). Bar, $20 \mu \mathrm{m}$.
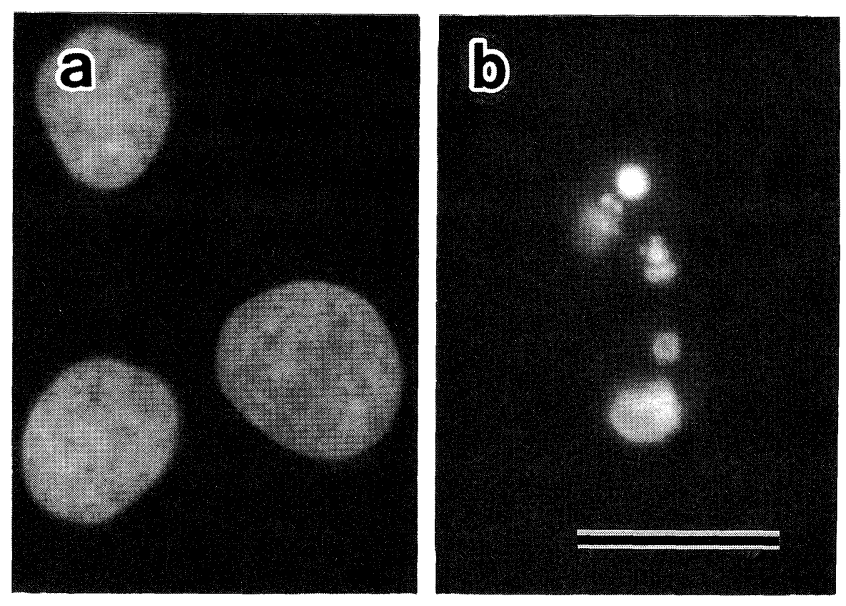

Fig. 3. Hoechst staining of nuclei in sparsely proliferating monolayer cells (a) and nuclei in cells collected from medium cultured for 5 days after a medium renewal of confluent $3 \mathrm{Y} 1$ culture (b). Bar, $3 \mu \mathrm{m}$.

Hoechst staining showed that all floating cells observed so far had pyknotic remnants of nuclei or multiple micropyknotic nuclei (Fig. 3). Electron microscopy revealed condensed and uniformly dense chromatin in the floating cells (Fig. 4a). The margins of the chromatin were sharply circumscribed. The cytoplasm had multiple vacuoles. The morphological features of the nuclei in the floating cells were analogous to apoptotic bodies $(1,2)$. On a thin section prepared perpendicularly to the surface of the substratum, we have found a cell just detaching from the substratum. The cell contained condensed chromatin and multiple vacuoles in cytoplasm (Fig. 4b), showing that the floating cells are detached from the monolayer after undergoing apoptotic process.

DNA fragmentation. To examine whether extracted DNA from the floating cells revealed a banding pattern that would indicate internucleosomal cleavage similar to that found in thymocytes $(23,24)$, a medium containing floating cells was collected from twenty 90 $\mathrm{mm}$ dishes. Gel electrophoresis of extracted DNA from the floating cells revealed a diffuse smear appearing but contained a characteristic "ladder" at a low molecular fragment region (Fig. 5). We noticed that DNA isolated from cells on the monolayer at the maximum cell density showed a more typical "ladder" with discrete strand length. The strand break distribution is in close agreement with double-strand break intervals of $180-200 \mathrm{bp}$ reported by apoptotic DNA isolated from thymocytes (24).

Engulfment of apoptotic corpuscles by intact cells. Because the laddering was more pronounced in monolayer cells at the maximum cell density, we have morphologically observed cells in the monolayer by Hoechst staining. The pyknotic nuclei or multiple frag- 

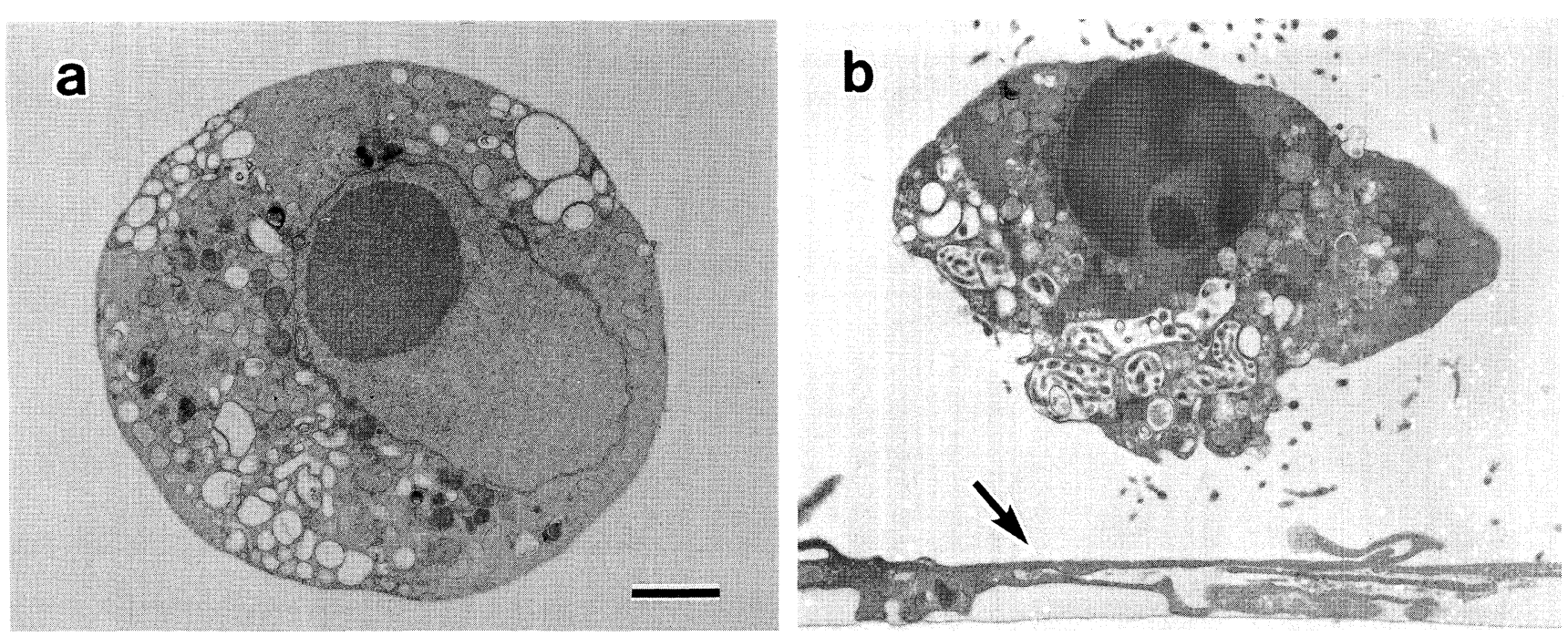

Fig. 4. Electron microscopic features of floating cells and of cells just detaching from the monolayer. Appearances of floating cell collected from medium cultured confluent $3 \mathrm{Y} 1$ cells for 5 days after renewal of medium (a). Cells fixed on a plastic-sheet were embedded in epoxy resin, and $90 \mathrm{~nm}$ section were prepared in parallel to the plastic sheet. Note a condensed and uniformly dense chromatin. Appearance of detaching cells on monolayer cells (b). Arrow indicates cytoplasm of cells on monolayer. 3Y1 cells were cultured until confluence on the plastic sheet and, at 3 days after medium renewal, cells were fixed and embedded in epoxy resin, and $90 \mathrm{~nm}$ sections were prepared in perpendicular to the surface of the sabstratum. Note an apoptotic cell just detaching from the monolayer. Bar, $2 \mu \mathrm{m}$.

mented nuclei as observed in floating cells were detected on the density-maximum population. Most of the pyknotic cells were observed to be in contact with another intact nucleus, as if the pyknotic cells were pushing against the intact nucleus. When the monolayer of density-maximum population was stained with acridine

\section{$123 \quad 3 \quad 4$}

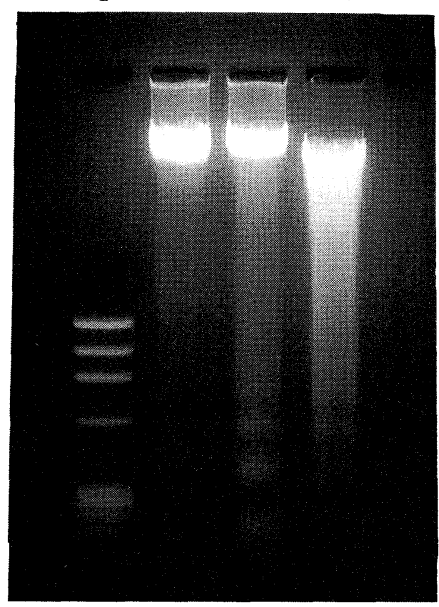

Fig. 5. Gel electrophoresis of isolated DNA from sparsely proliferating cells (lane 2 ), from cells on monolayer cultured toward confluency and at the 3rd day after a medium renewal (lane 3) and from floating cells collected from media cultured for 5 days after the medium renewal (lane 4). Note a typical DNA fragmentation in lanes 3 and 4. Lane 1 is the molecular size marker of $\phi \times 174 / \mathrm{Hae}$ III digestion. orange, apoptotic cells stained brightly and were found within the cytoplasm of a cell with intact nucleus. The nuclei of the intact cells were deformed by pressure from apoptotic bodies and the margin of some apoptotic cells were darkly bordered (Fig. 6). The appearance was a previously unreported feature in the cell culture system and suggested to us the engulfment of apoptotic cells (1). Electron microscopy revealed that the encapsu-

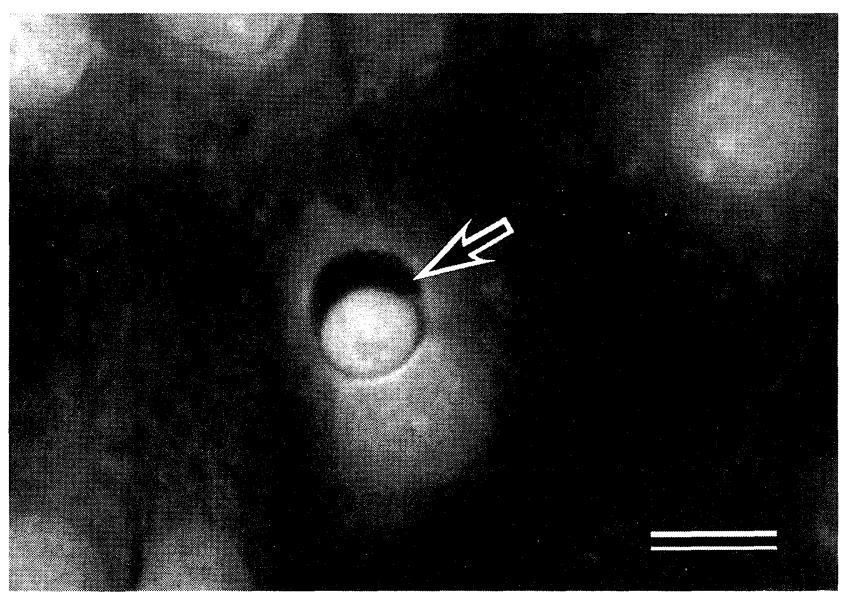

Fig. 6. Acridine orange staining of monolayer cells. $3 Y 1$ cells were cultured until a stationary cell density at confluence and cells cultured for 3 days after medium renewal were fixed and stained with acridine orange. Note an apoptotic cell (bright fluorescence, arrow) within the cytoplasm of cell with intact nuclei (faint fluorescence). Bar, $3 \mu \mathrm{m}$. 

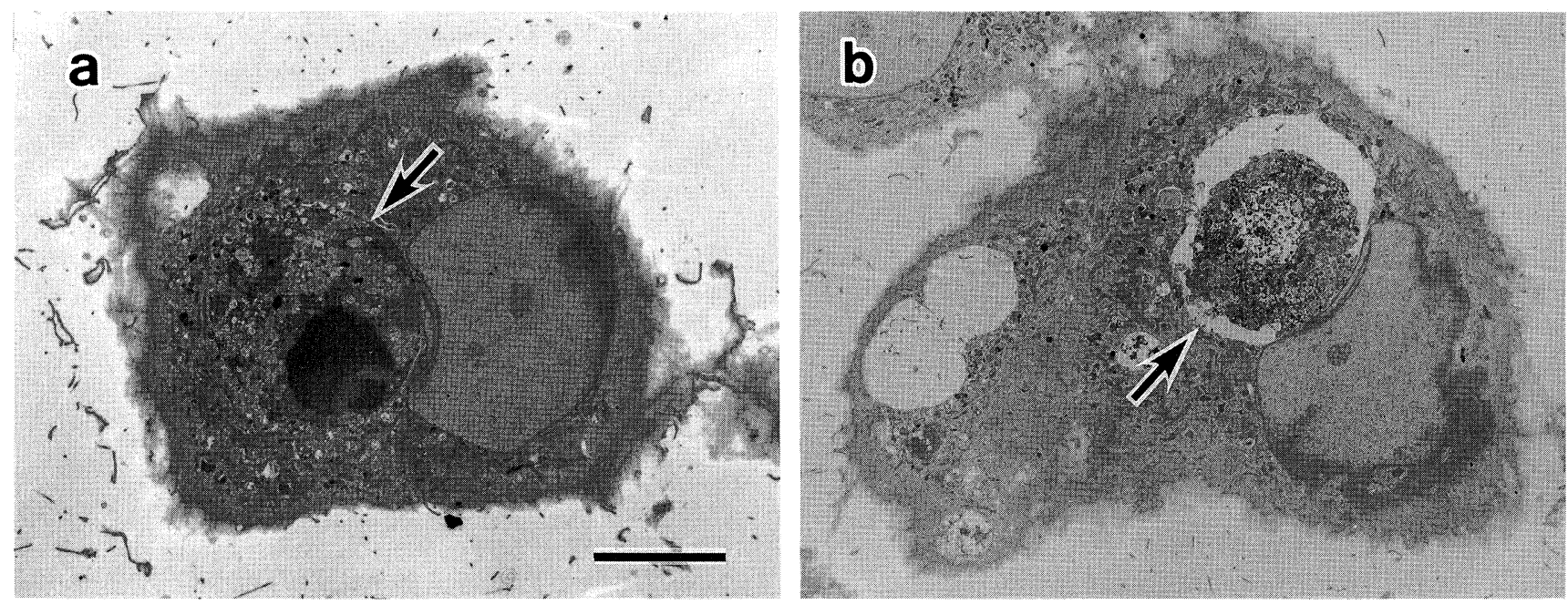

Fig. 7. Electron microscopy of apoptotic bodies (arrows) within cytoplasm of intact cells (a and b). Monolayer cells on the plastic sheet were prepared in the same culture conditions as cells in Fig. 6. Bar, $5 \mu \mathrm{m}$.

lated cells had condensed chromatin as observed in floating cells, showing that the encapsulated cell is an apoptotic body engulfed by a cell with intact nuclei (Fig. 7). Some corpuscles bordered with electron lucent materials had vacuolated remnants of nuclei and unclear plasma membrane (Fig. 7), suggesting that the engulfed corpuscles were digested in the cytoplasm of the intact cell. The results show that the apoptotic cells which appear after going through the maximum cell density are lost either by being thrown up from the monolayer or by being engulfed by neighboring intact cells to maintain post-confluence stationary cell density.

\section{DISCUSSION}

In this report, we have shown that cell death in the process of entering the stationary cell density in rat $3 \mathrm{Y} 1$ culture is apoptosis, in terms of morphological criteria and typical DNA fragmentations of floating cells in medium. The apoptotic nuclei and typical DNA fragmentation have been observed not only in floating cells in medium but also in cells on the monolayer in a postconfluent state. Furthermore, the majority of the apoptotic bodies in the monolayer have been found within the cytoplasm of intact cells. Phagocytosis of apoptotic bodies has been found in histological sections of healthy adult tissues and has been reported as an important stage of apoptosis by Kerr et al. (1). They have shown that apoptotic bodies are phagocytosed by connective tissue cells (sinusoid-lining cells, "histocytes") under physiological conditions in post-natal life and by epithelial cells during embryogenic development and in various pathological states in adult animals. Such phenomenon as engulfment of a whole cell by a neighbor- ing cell has been reported in a clonal cell culture. Recently Bates et al. (25) has reported that the LIM 1863 colon carcinoma cell line, which grows as organoids in suspension, shows the phenomenon of engulfment when two single cells come into contact after disrupting the organoid structure and reseeding desegregating single cells. The encapsulated cell in the doublet of cells had a wellpreserved nucleus, membrane, mitochondrial cristae and other organelles, and the doublet cells have been shown to have an important role in the reformation of the organoid structure in suspension. But the fate of the encapsulated cells is not known. Hall et al. (26) has reported that monolayers of fibroblasts can selectively phagocytose apoptotic neutrophils. The phenomena suggests that, even in a clonal cell culture, one cell can take over such large structures as whole cells under specific conditions. Transport of extracellular materials into cultured fibroblastic cells via micropinocytotic vesicles is well-known. Some fibroblastic cells have been reported to have large vacuoles containing the imbibed materials $(27,28)$, and to ingest carmine dye particles (29), collagen $(30)$, mast cell granules $(31,32)$ and fibronectin-coated $(33,34)$, poly-L-lysine-coated, or UV-irradiated latex beads (35). It is perhaps not surprising that fibroblastic $3 \mathrm{Y} 1$ cells can engulf large structures such as apoptotic bodies. Most of the apoptotic bodies we detected in the monolayer were within the cytoplasm of the intact cells. We could not detect any cells engulfing a cell with an intact nucleus. The apoptotic bodies may have been rapidly and specifically engulfed by neighboring cells, possibly because of rapid changes in the properties of their surface membranes. The data show that density-dependent cell death in rat 3Y1 cells is apoptosis and suggest that apoptosis is one of basic mechanisms 
in maintaining the post-confluence stationary cell population under routine culture conditions.

Density-dependent cell death has been shown to be an important process during adjustment of cell densities in mouse $3 \mathrm{~T} 3$ cell populations (10) and rat $3 \mathrm{Y} 1$ cell populations (20). The present result provides evidence for involvement of apoptosis in density-dependent cell death. This phenomenon will in all likelihood occur in some permanent cell lines which exhibit density-dependent inhibition of cell proliferation, "contact inhibition", and not in others which have presumably lost the ability to undergo apoptosis or the ability to engulf apoptotic cells. We have previously suggested that decreased cell losses following cell increases upon medium renewals are a common phenotype of many $\mathrm{N}$-methyl- $\mathrm{N}^{\prime}$-nitro$\mathrm{N}$-nitrosoguanidine transformed sublines (20). Genetic defects involving an apoptotic pathway in the densitydependent regulation of $3 \mathrm{Y} 1$ cells may be one of the causes of the development of morphologically dense transformed foci in vitro and the development of tumors in vivo. Finally, 3Y1 cells and other established "normal" cell lines, exhibiting density-dependent inhibition of cell division, should be advantageous for addressing the physiological process of cell death coordinated with density-dependent regulation of cell proliferation.

Acknowledgements. We are grateful to Mr. T. Wiltshire for reading this manuscript.

\section{REFERENCES}

1. Kerr, J.F.R., Wyllie, A.H., and Currie, A.R. 1972. Apoptosis: A basic biological phenomenon with wide-ranging implications in tissue kinetics. Br. J. Cancer, 26: 239-257.

2. KerR, J.F.R. and Harmon, B.V. 1991. The Molecular Basis of Cell Death. In Apoptosis (Tomei, L.D. and Cope, F.O., eds.). Cold Spring Harbor Laboratory Press, New York. pp.529.

3. Holly, R.W. and Kiernan, J.A. 1968. Contact inhibition of cell division in 3T3 cells. Proc. Natl. Acad. Sci. USA, 60: 300304.

4. Dulbecco, R. 1970. Topoinhibition and serum requirement of transformed and untransformed cells. Nature, 227: 802-806.

5. Dulbecco, R. and Elkington, J. 1973. Conditions limiting multiplication of fibroblastic and epithelial cells in dense cultures. Nature, 246: 197-199.

6. Holly, R.W., ARmour, R., Baldwin, J.H., Brown, K.D., and YEH, Y.C. 1977. Density-dependent regulation of growth of BSC-1 cells in cell culture: control of growth by serum factors. Proc. Natl. Acad. Sci. USA, 74: 5046-5050.

7. LyNCH, M.P., NaWAZ, S., and Gerschenson, L.E. 1986 . Evidence for soluble factors regulating cell death and cell proliferation in primary cultures of rabbit endometrial cells grown on collagen. Proc. Natl. Acad. Sci. USA, 83: 4784-4788.

8. Rotello, R.J., Hocker, M.B., and GerChenson, L.E. 1989. Biochemical evidence for programmed cell death in rabbit uterine epithelium. Am. J. Pathol., 134: 491-494.

9. Rotello, R.J., Lieberman, R.C., Purchio, A.F., and
GeRsChenson, L.E. 1991. Coordinated regulation of apoptosis and cell proliferation by transforming growth factor $\beta 1$ in cultured uterine epithelial cells. Proc. Natl. Acad. Sci. USA, 88: $3412-3415$.

10. VAN DER BosCh, J. 1978. Complex population kinetics in $3 T 3$ and SV40-3T3 cell cultures: Involvement of cell division, inhibition of divisions and death of cells. Exp. Cell Res., 117: 111119.

11. TomeI, L.D., ShaPiro, J.P., and CoPe, F.O. 1993. Apoptosis in $\mathrm{C} 3 \mathrm{H} / 10 \mathrm{~T} 1 / 2$ mouse embryonic cells: Evidence for internucleosomal DNA modification in the absence of double strand cleavage. Proc. Natl. Acad. Sci. USA, 90: 853-857.

12. Galli, G. and Fratelli, M. 1993. Activation of apoptosis by serum deprivation in a teratocarcinoma cell line: Inhibition by L-acetylcarnitine. Exp. Cell Res., 204: 54-60.

13. Scott, W., Lowe, H., Ruley, E., Jacks, T., and Housman, D.E. 1993. p53-Dependent apoptosis modulates the cytotoxicity of anticancer agents. Cell, 74: 957-967.

14. Kimura, G., Itagaki, A., and Summers, J. 1975. Rat cell line $3 \mathrm{Y} 1$ and its virogenic polyoma- and SV40-transformed derivatives. Int. J. Cancer, 15: 694-706.

15. OKUdA, A. and Kimura, G. 1978. Serum stimulation of DNA synthesis in rat $3 \mathrm{Y} 1$ cells: Dependence on cell density, serum concentration, and ratio of cell number to medium volume. Exp. Cell Res., 111: 55-62.

16. OKuda, A. and CoOper, S. 1989. The continuum model: an experimental and theoretical challenge to the G1-model of cell cycle regulation. Exp. Cell Res., 185: 1-7.

17. Ohno, K., Okuda, А., Оhtsu, M., and Kimura, G. 1984 . Genetic analysis of control of proliferation in fibroblastic cells in culture. I. Isolation and characterization of mutants temperature-sensitive for proliferation or survival of untransformed deployed rat cell line 3Y1. Somat. Cell Mol. Genet., 10: 17-28.

18. Ohno, K. and KimUra, G. 1984. Genetic analysis of control of proliferation in fibroblastic cells in culture. II. Alteration in proliferative and survival phenotypes in a set of temperature-sensitive mutants of rat $3 \mathrm{Y} 1$ cells after infection or transformation with simian virus 40. Somat. Cell Mol. Genet., 10: 29-36.

19. Katsumoto, T., Higaki, K., Ohno, K., and Onodera, K. 1994. The orientation of primary cilia during the wound response in 3Y1 cells. Biol. Cell, 81: 17-21.

20. Ohno, K., Zaitsu, H., and Kimura, G. 1987. Maintenance of postconfluence stationary cell density by transient increase and decrease in cell number upon medium renewals in rat 3Y1 fibroblasts: Diminution of the decrease in cell number after cell transformation by N-methyl-N'-nitro-N-nitrosoguanidine. Fukuoka Acta Med., 78: 569-577.

21. White, K., Grether, M.E., Abrahams, J.M., Young, L., FARRell, K., and Steller, H. 1994. Genetic control of programmed cell death in Drosophila. Science, 264: 677-683.

22. Gavrieli, Y., Sherman, Y., and Ben-Sasson, S.A. 1992. Identification of programmed cell death in situ via specific labeling of nuclear DNA fragmentation. J. Cell Biol., 119: 493-501.

23. WylliE, A.H. 1980. Glucocorticoid-induced thymocyte apoptosis is associated with endogeneous endonuclease activation. Nature, 284: 555-556.

24. Arrends, M.G., Morris, R.G., and Wyllie, A.H. 1990. Apoptosis. The role of the endonuclease. Am. J. Pathol., 136: 593-608.

25. Bates, R.C., Buret, A., van Helden, D.F., Horton, M.A., and BuRNs, G.F. 1994. Apoptosis induced by inhibition of intracellular contact. J. Cell Biol., 125: 403-415.

26. Hall, S.E., Savill, J.S., Henson, P.M., and Haslett, C. 
1994. Apoptotic neutrophils are phagocytosed by fibroblasts with participation of the fibroblast vitronectin receptor and involvement of a mannose/fucose-specific lectin. J. Immunol., 153: 3218-3227.

27. Gordon, G.B., Miller, L.R., and Bensch, K.G. 1965. Studies on the intracellular digestive process in mammalian tissue culture cells. J. Cell Biol., 25: 41-55.

28. BRoCK, M.A. and HAY, R.J. 1971. Comparative ultrastructure of chick fibroblasts in vitro at early and late stages during their growth span. J. Ultrastruct. Res., 36: 291-311.

29. Vasiliev, J.M., Gelfand, I.M., Domnira, L.V., Zacharova, O.S., and LJUBimov, A.V. 1975. Contact inhibition of phagocytosis in epithelial sheets: alterations of cell surface properties induced by cell-cell contacts. Proc. Natl. Acad. Sci. USA, 72: 719-722.

30. Melcher, A.H. and Chan, J. 1981. Phagocytosis and digestion of collagen by gingival fibroblasts in vivo: a study of serial sections. J. Ultrastruct. Res., 77: 1-36.
31. Tannenbaum, S., Oertel, H., Henderson, W., and Kaliner, M. 1980. The biologic activity of mast cell granules. I. Elucidation of inflammatory responses in rat skin. J. Immunol., 125: 325-335.

32. Subba-Rao, P.V., Friedman, M.M., Atkins, F.M., and MetCalfe, D.D. 1983. Phagocytosis of mast cell granules by cultured fibroblasts. J. Immunol., 130: 341-349.

33. GRINNELL, F. 1980. Fibroblast receptor for cell substratum adhesion: studies on the interaction of baby hamster kidney cells with latex beads coated by cold insoluble globulin (plasma fibronectin). J. Cell Biol., 86: 104-112.

34. GRINNELL, F. 1984. Fibroblast spreading and phagocytosis: similar cell responses to different-sized substrata. J. Cell Physiol., 119: 58-64.

35. Okada, Y., Tsuchiya, W., Toda, T., Yanno, J., and Yano, H. 1981. Phagocytosis activity and hyperpolarising responses in L-strain mouse fibroblasts. J. Physiol., 313: 101-119.

(Received for publication, September 30, 1996 and in revised form, November 15, 1996) 